\title{
Long Non-Coding RNAs in Oral Submucous Fibrosis: Their Functional Mechanisms and Recent Research Progress
}

\author{
Yaodong $\mathrm{He}^{1, *}$ \\ Wei Wang ${ }^{l}$ * \\ Pingping Jiang ${ }^{2}$ \\ Lin Yang' \\ Qi Guo' \\ Junwei Xiang' \\ Yuling Gao' \\ Yuanyin Wang' \\ Ran Chen (D) ${ }^{\prime}$
}

'College \& Hospital of Stomatology, Anhui Medical University, Key Laboratory of Oral Diseases Research of Anhui Province, Hefei, Anhui Province, 230032, People's Republic of China; ${ }^{2}$ School of Pharmacy, Anhui Medical University, Hefei, Anhui Province, 230032, People's Republic of China

*These authors contributed equally to this work
Correspondence: Yuanyin Wang; Ran Chen College \& Hospital of Stomatology, Anhui Medical University, Key Laboratory of Oral Diseases Research of Anhui Province, Hefei, Anhui Province, 230032, People's Republic of China

Emailwyy1970548@sohu.com;

ahmuchenran@I63.com

\begin{abstract}
Many studies have shown that most genomes are transcribed into non-coding RNAs (ncRNAs), including microRNAs (miRs) and long non-coding RNAs (lncRNAs), which can affect different cell characteristics. LncRNAs are long heterologous RNAs that regulate gene expression and various signaling pathways during homeostasis and development. Studies have shown that a lncRNA is an important regulatory molecule that can be targeted to change the physiology and function of cells. Expression or dysfunction of lncRNAs is closely related to various genetic, autoimmune, and metabolic diseases. The importance of ncRNAs in oral submucosal fibrosis (OSF) has garnered much attention in recent years. However, most research has focused on miRs. The role of these molecules in OSF is incompletely understood. This review focuses on the emerging role and function of lncRNAs in OSF as novel regulators. Finally, the potential functional role of lncRNAs as biomarkers for OSF diagnosis is also described. LncRNAs are expected to become a new therapeutic target, but more research is needed to understand their biological functions more deeply.
\end{abstract}

Keywords: oral submucous fibrosis, long non-coding RNAs, function, mechanism, biomarker

\section{Introduction}

Oral submucosal fibrosis (OSF) is a chronic inflammatory oral disease that can cause scarring and tissue fibrosis. ${ }^{1}$ OSF symptoms include dry mouth, pain, dysgeusia, restricted movement of the tongue, cramps, difficulty in swallowing, and changes in tone activity. ${ }^{2}$ Due to the high prevalence of malignant transformation $(1.5-15 \%)$, the mortality risk from OSF is worrisome. ${ }^{3}$

OSF pathogenesis is incompletely understood, but is thought to be caused by a combination of factors: chewing areca (betel) nut, immune process, genetic factors, and nutritional deficiencies. ${ }^{4}$ According to current epidemiological studies and research, chewing areca nut is the most prominent risk factor for OSF. ${ }^{5}$ Arecoline in areca nut is the primary alkaloid that causes OSF. ${ }^{6-8}$ Arecoline can increase the expression of growth factors and cytokines in fibroblasts, as well as promote collagen deposition and prevent collagen breakdown. ${ }^{9}$ Transforming growth factor- $\beta$ (TGF- $\beta$ ) is the main cytokine involved in OSF progression. TGF$\beta$ stimulates collagen formation significantly by activating the procollagen genes collagen type I (COL1)A2, COL3A1, COL6A1, COL6A3 and COL7A $1 .{ }^{10}$ TGF- $\beta$ can also upregulate expression of lysyl oxidase (which is a crosslinked product of 
collagen fibers) and enhance procollagenase expression. ${ }^{11}$ Flavonoids are the other important components of areca nut, and their synergistic effect with alkaloids can induce OSF. $^{12}$

Inflammatory cells have also been linked to OSF initiation. Areca nut-induced mucosal inflammation attracts activated $\mathrm{T}$ cells and macrophages, as well as stimulating production of basic fibroblast growth factors (bFGF) and TGF- $\beta 1$. Continued overexpression of bFGF in oral cells can cause obstacles to collagen deposition in OSF. ${ }^{13}$ Arecoline also upregulates expression of other proinflammatory and pro-fibrotic cytokines, such as interleukin (IL)-1, IL6 , IL-8, tumor necrosis factor (TNF)- $\alpha$, platelet-derived growth factor (PDGF), and keratinocyte growth factor. ${ }^{14}$ The wound-healing response is activated by cell inflammation, which reduces matrix metalloproteinase (MMP) expression while increasing tissue inhibitor of matrix metalloproteinase (TIMP) expression. ${ }^{15}$ Reduced levels of gelatin-degrading proteases (eg, MMP-2, MMP-9) secreted by fibroblasts and increased levels of TIMP-1 lead to a loss of extracellular matrix (ECM) balance in OSF. ${ }^{16}$

In addition, malnutrition (eg, insufficiency of proteins and vitamins, or anemia), as well as alterations in serum levels of iron and copper, are related to OSF development. $^{17,18}$ Serum iron deficiency can alter the epithelial structure, increase mucosa permeability, and compromise its barrier function. Copper aids in fibrosis development by increasing the activity of lysyl oxidase. ${ }^{19}$ It has been shown that people who are deficient in iron or vitamin B12 are more susceptible to OSF. ${ }^{20}$ The molecular and cellular mechanisms of OSF have been explored extensively, but some features have not been focused upon. For instance, OSF onset is recessive; some patients take about 2-20 years to develop symptoms. ${ }^{21}$ The lack of an approach for early detection for this type of chronic occult disease is a problem. Tissue biopsy is the most common method of diagnosis. The biopsy specimens of patients with early OSF show aberrant proliferative alterations. ${ }^{22}$ Hence, early detection of precancerous lesions is crucial, as is knowledge of their pathophysiology and diagnostic procedures, in lowering the risk of malignant OSF.

Analyses of gene-regulatory networks have concentrated chiefly on protein-coding genes. Genomic analysis of the human genome has demonstrated that $\sim 90 \%$ of transcripts are non-coding (nc)RNAs. ${ }^{23}$ Recent studies have shown that ncRNAs are essential regulators of gene expression and the signal transduction of cells. ${ }^{24}$ Increasing evidence suggests that ncRNAs are critical determinants of gene expression during OSF. ${ }^{25}$ Zheng et $\mathrm{al}^{26}$ found microRNA (miR)-203 expression to be downregulated significantly in OSF tissues compared with that in normal buccal mucosa tissues. Upregulation of miR-203 expression inhibited cell growth and increased expression of the proteins of cytokeratin 19 and E-cadherin while suppressing expression of $\mathrm{N}$-cadherin and vimentin. Expression of miR-200b and miR-200c was downregulated in OSF specimens. Arecoline treatment reduced miR-200c expression in buccal mucosal fibroblasts. ${ }^{27,28}$ By targeting zinc finger E-box binding homeobox (ZEB) 1 and ZEB2, miR-200c and miR-200b increased E-cadherin expression. ZEB1 interacts with the promoter of $\alpha$-smooth muscle actin ( $\alpha$-SMA) and causes $\alpha$-SMA overexpression in myofibroblasts during fibrogenesis. Therefore, the potential functional role of ncRNAs as targets and biomarkers for diagnosis and treatment has been proposed.

Long non-coding (lnc)RNAs are a family of regulatory non-coding RNA molecules with a transcript length $>200$ nucleotides (nt). ${ }^{29}$ They are believed to play a part in physiological conditions and various human diseases: cancer, metabolic diseases, and cardiovascular diseases. ${ }^{30}$ Recent studies have shown that lncRNAs are key regulators in determining myofibroblast activation and OSF. ${ }^{31,32}$ Expression of the lncRNA GAS5-AS1 is downregulated in OSF tissue. $^{33}$ GAS5-AS1 inhibits phosphorylation of Smad2, as well as TGF/Smad signaling and $\alpha$-SMA expression in myofibroblasts. LINC00084 has the opposite effects. LINC00084 shows aberrantly high expression in OSF tissues and myofibroblasts. ${ }^{34}$ The lncRNAs related to fibrosis pathogenesis mainly involve cell macromolecules (eg, chromatin, protein, RNA) ${ }^{35}$ The role of ncRNAs (especially lncRNAs) in fibrosis is being investigated gradually, and the underlying mechanism between them and OSF must be clarified.

In this review, we summarize recent advances in lncRNA research, as well as the molecular mechanisms and functions of lncRNAs during OSF. Finally, we discuss the potential role of a lncRNA-based diagnosis for OSF.

\section{Overview of IncRNAs}

LncRNAs are a new category of ncRNA transcripts. So far, $\sim 30,000$ lncRNA transcripts in the human genome have been identified. ${ }^{36}$ Most lncRNAs are made by RNA polymerase II, and have little coding ability. ${ }^{37,38}$ However, they have many common features with mRNA, such as capping of the $5^{\prime}$ end, which usually contains exons and introns. ${ }^{39,40}$ lncRNAs have 


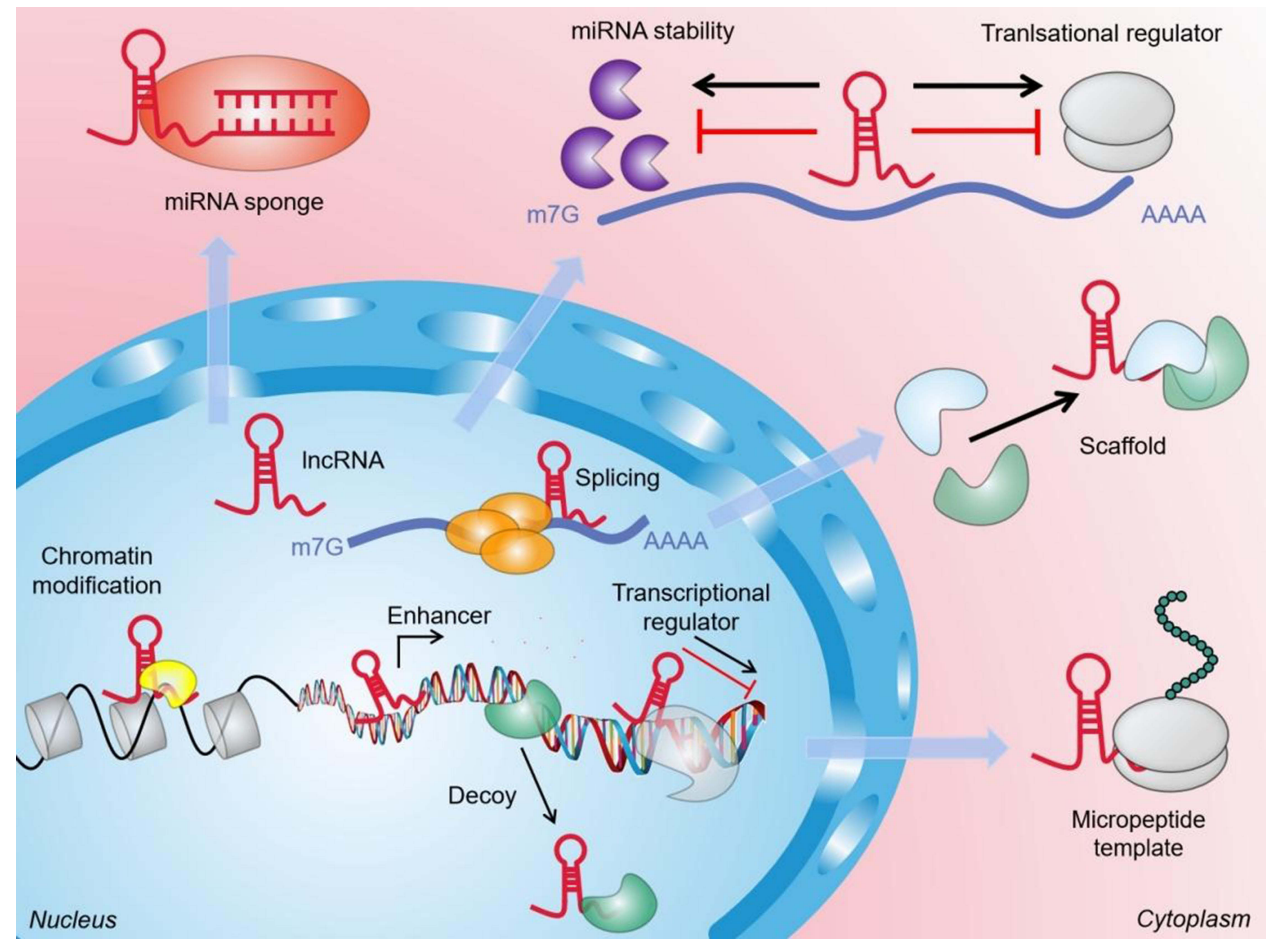

Figure I The general function and mechanism of LncRNA. (I) In the nucleus, IncRNAs can guide chromatin modifiers and various transcriptional regulators to DNA, thereby inhibiting and/or activating gene expression. LncRNAs can be used as enhancers of target gene activation. They can also act as molecular baits to move proteins away from specific DNA locations. (2) In the cytoplasm, IncRNAs can be used as scaffolds to bring two or more proteins into the complex. In addition, they also act as sponges for other transcripts or proteins, as protein templates, or regulate mRNA degradation and translation.

a wide range of functions, which may be due to their ability to bind DNA, RNA, or proteins. These interactions can enable use of a lncRNA as a guide, enhancer, decoy, or scaffold for post-transcriptional and post-translational regulation of gene expression (Figure 1). ${ }^{41,42}$ For example, several lncRNAs have been shown to interact with chromatin modifiers (eg, polycomb repressor complex-2) and recruit them to target gene promoters to activate or inhibit their cis or trans transcription (usually at multiple sites). ${ }^{43,44}$ Conversely, a lncRNA can also act as a "bait molecule" to seize regulatory factors in the nucleus or cytoplasm. If a lncRNA is transcribed, it binds directly to some protein molecules, such as chromosome-folding proteins or transcription regulators, thereby weakening the function of the protein. ${ }^{45}$ The IncRNAs in cytoplasm can bind directly to miR molecules, prevent them from binding to target genes, thereby upregulating expression of target genes. ${ }^{46}$ lncRNAs can be used as "central platforms" to enable different macromolecular complexes to be assembled, thereby promoting information fusion and integration between different signaling pathways. ${ }^{47,48}$ In addition, lncRNA can be used as secondary activators or enhancers for activation of target genes. lncRNAs and enhancer RNAs (eRNAs) can promote expression of protein-coding genes (PCGs) that are very close to their enhancers through preformed chromatin loops, thereby recruiting chromatin-activation complexes to the promoters of PCGs. ${ }^{49,50}$

Recent studies have shown that lncRNA is the primary vector of aging, ${ }^{51}$ cancer, $^{52}$ and neurological diseases. ${ }^{53}$ Increasing numbers of studies have shown that lncRNAs are also involved in the pathologic process of OSF, but the relationship between these processes is unclear. Therefore, a potential new link between lncRNAs and OSF opens up a new field for treatment and diagnosis.

\section{Function Role of IncRNAs in OSF}

OSF is a multi-factor, multi-step process involving genes, epigenetics, and the environment. Regulation of lncRNAs cannot be ignored in the occurrence and development of OSF. Accordingly, we elaborate on the regulation of lncRNAs in OSF (Table 1). ${ }^{31-33,54-57}$

\section{$\mathrm{HI} 9$}

The H19 gene is expressed as a single allele on the chromosomes of maternal origin in mice and humans. H19 shares a common regulatory sequence with other genes (including 
Table I LncRNAs are Involved in Regulating Oral Submucosal Fibrosis

\begin{tabular}{|l|c|c|l|c|}
\hline IncRNA & Targets & Expression & Functions & Reference \\
\hline LINC00974 & TGF- $\beta$ & + & Activates TGF- $\beta /$ Smad signaling to promote OSF & [54] \\
\hline HI9 & miR-29b & + & Suppresses OSF via HI9/miR-29b/COLIAI axis. & [3I] \\
\hline HOTTIP & TNF- $\alpha$ & + & $\begin{array}{l}\text { Promotes the persistent activation of myofibroblasts as well as the chronic } \\
\text { inflammation and collagen deposition. }\end{array}$ & [32] \\
\hline HIFIA-ASI & - & + & $\begin{array}{l}\text { Promotes the arecoline-induced migration activity of human oral mucosal } \\
\text { fibroblasts }\end{array}$ & [55] \\
\hline LINC003I2 & YBXI & + & Promotes OSF via LINC003I2/YBXI axis. & [56] \\
\hline LINC00084 & miR-204 & + & Promotes myofibroblast transdifferentiation of buccal mucosal fibroblasts & [33] \\
\hline GAS5-ASI & P-Smad2 & - & Attenuate the activation of myofibroblasts. & [57] \\
\hline ADAMTS9-AS2 & - & - & Suppresses OSF via AKT signaling pathway. & \\
\hline
\end{tabular}

insulin-like growth factor-2) in the cluster. ${ }^{58}$ H19 encodes a 2.3-kb non-coding RNA, is expressed abundantly on almost all maternal alleles in fetal tissues, but its expression drops sharply after birth and it is expressed only in the myocardium and skeletal muscle. ${ }^{59,60} \mathrm{H} 19$ shows high expression in cancers of different tissue origins, owing to the loss of imprinting in some cases. H19 has been shown to have carcinogenic and anti-cancer properties simultaneously. ${ }^{61}$ Reports have suggested that $\mathrm{H} 19$ is related to various diseases, including those involving tissue fibrosis. ${ }^{62-65}$ There is clear evidence that $\mathrm{H} 19$ is involved in OSF pathogenesis. Yu et $\mathrm{al}^{31}$ showed H19 expression in OSF tissues to be upregulated. Abnormal expression of H19 can enhance myofibroblast activity, such as the contractility and migration ability of collagen gel. $\mathrm{H} 19$ acts as a "sponge" for miR-29b in fibrotic buccal mucosal fibroblasts (fBMFs) and prevents miR-29b from binding directly to the 30th untranslated region of COL1A1. The latter is considered to be the main component of excessive collagen deposition in fibrosis. ${ }^{66}$ Downregulation of miR-29b expression augments COL1A1 expression, whereas suppression of H19 reduces COL1A1 expression. Ectopic expression of miR-29b can ameliorate the phenotype of fBMFs and expression of $\alpha$-SMA and fibronectin- $1 .{ }^{31}$ These discoveries require further research to ascertain the role of H19 in OSF progression.

\section{HOXA Terminal Transcript (HOTTIP)}

HOTTIP is a lncRNA encoded by the 5' terminal genomic region of HOXA ${ }^{67}$ HOTTIP is a $3764-n t$ spliced, polyadenylated lncRNA. ${ }^{68}$ Its genomic location gives it a role in activation of several 5 ' HOXA genes. ${ }^{68}$ Functional studies have shown that the chromosomal loop enables HOTTIP to lie adjacent to HOXA, HOTTIP binds directly to WD repeat domain (WDR)5 protein, and then the WDR5/MLL complex recruits across HOXA sites, leading to methylation of histone 3 lysine 4 , and activation of HOXA transcription. ${ }^{69}$ This transfer of signals from the higher-order chromosomal configuration to the chromatin code $^{69}$ not only means that HOTTIP is involved in the development process but also enhances its role as a cancerrelated lncRNA. Huang et $\mathrm{al}^{70}$ demonstrated that HOTTIP can be used as a biomarker for overall survival of oral squamous cell carcinoma (OSCC) patients. HOTTIP also promotes OSF development. Lee et $\mathrm{al}^{32}$ found that HOTTIP expression was upregulated in human fBMFs in a study on OSF. Inhibition of HOTTIP expression reduced myofibroblast activity (contraction and migration ability of collagen gel) and the development of proinflammatory cytokines (IL-6, TNF- $\alpha$ ). Furthermore, they showed HOTTIP expression to be positively associated with OSFrelated variables, including COL1A1, TGF- $\beta$, and $\alpha$-SMA, indicating that HOTTIP is an oncogene and fibrosis mediator. Those data point to a possible mechanism for HOTTIP in OSF, which could lead to new treatment options.

\section{Hypoxia-Inducible Factor IA Antisense RNA I (HIFIA-ASI)}

HIF1A-AS1 is a natural antisense transcript derived from the HIF-1 $\alpha$ sequence, which encodes the 30th untranslated 
region of HIF-1 $\alpha$ mRNA. ${ }^{71}$ HIF1A-AS1 is located on chromosome 14, and has a length of $2100 \mathrm{nt}^{72}$ Increasing numbers of studies have shown that HIF-1 $\alpha$ dysfunction is related to various oral diseases in humans, including cancer and fibrosis. Lee et $\mathrm{al}^{73}$ found that HIF$1 \alpha$ expression in areca nut chewing-related OSCC was upregulated significantly. Uehara et $\mathrm{al}^{74}$ revealed that HIF-1 $\alpha$ may play an important part in the lymph-node metastasis and prognosis of OSCC patients. According to several studies, HIF-1 $\alpha$ expression is upregulated in OSF tissues, which indicates changes in the proliferation, maturation, and metabolic adaptation of cells, and increases the possibility of malignant transformation. ${ }^{75}$ Wang et $\mathrm{al}^{55}$ demonstrated that HIF1A-AS1 expression was upregulated abnormally in OSF tissues and fBMFs, and that arecoline could induce an increase in HIF1A-AS1 expression in BMFs. Simultaneously, they discovered that HIF1A-AS1 knockout inhibited the migration ability of BMFs stimulated by arecoline and inhibited the myofibroblast activity induced by arecoline. Therefore, measuring HIF1A-AS1 expression in OSF tissue aids understanding of whether HIF1A-AS1 is involved in OSF carcinogenesis.

\section{Linc003 12}

LINC00312 (also known as NAG7) is located on chromosome 3p25.3. ${ }^{76,77}$ LINC00312 is a transmembrane protein containing phosphorylation sites for protein kinase $\mathrm{C}$ and sites for myristyl alcohol. LINC00312 was initially reported in nasopharyngeal cancer. ${ }^{78}$ Studies have shown that LINC00312 can regulate cancer progression through numerous pathways, compounds, and miRs. ${ }^{79-81}$ LINC00312 can downregulate expression of cyclin B1 in cancer cells and induce cell-cycle arrest in the G2-M phase, thereby inhibiting cell proliferation and tumor progression in vivo. ${ }^{81}$ However, unlike the inhibitory effect of LINC00312 in various types of cancer, Yu et al ${ }^{81}$ discovered that LINC00312 expression in human OSF tissues was increased. Furthermore, fibrotic factors such as $\alpha$-SMA, COL1A1, and fibronectin are linked favorably with LINC00312 expression. $\alpha$-SMA has been demonstrated to upregulate the contractile activity of fibroblasts, ${ }^{82}$ and is a marker of myofibroblasts. Fibronectin deposition also causes OSF. ${ }^{83}$ Inhibition of LINC00312 expression has been shown to reduce myofibroblast activity, including the contraction and migration of collagen gel, wound healing, as well as the gene expression of myofibroblast markers. In addition, Y-box-binding protein (YBX)1 expression is regulated by LINC00312. The myofibroblast activity induced by LINC00312 was found to be restored after YBX1 knockout. Those results indicate that LINC00312-mediated myofibroblast activation requires YBX1. Overall, those findings have revealed that LINC00312 may be involved in the fibrosis process of OSF and regulate OSF progression. The LINC00312/YBX1 axis may become a target for developing treatments for OSF.

\section{Growth Arrest Special (GAS)5}

GAS5 is the host gene of small nucleolar RNA (snoRNA). GAS5 is located on chromosome 1q25, and has a total length of $\sim 630 \mathrm{nt}^{84}$ GAS5 in humans comprises 12 non-conserved exons, which encode 10 box C/D snoRNAs and two mature IncRNAs (GAS5a and GAS5b) in its introns. GAS5 is a 5' terminal oligopyrimidine chain (5' top) RNA, and is characterized by an upstream oligopyrimidine chain sequence. ${ }^{85}$ GAS5 transcripts show various alternative splicing patterns; although GAS5 has a short open reading frame (ORF), the putative ORF does not seem to encode functional proteins, and its role may be as a snoRNA host gene. ${ }^{86}$ GAS5 may exert a functional effect by interacting with steroid receptors that inhibit its action. ${ }^{87}$ GAS5 was discovered in normal murine fibroblasts, and was identified as a potential tumor-suppressor gene overexpressed during growth arrest. ${ }^{88}$ GAS5-mediated glucocorticoid-dependent transcription in epithelial cells serves as a "decoy" for glucocorticoid response element (GRE) to compete with DNA GRE for binding to the DNAbinding domain of the glucocorticoid receptor, thereby reducing cell metabolism. ${ }^{89}$ According to a growing body of research, GAS5-AS1 overexpression lowers the markers of endothelial-mesenchymal transition (EMT) ${ }^{90}$ Lin et a ${ }^{33}$ discovered that GAS5-AS1 expression in OSF samples and fBMFs was reduced. Increased expression of GAS5-AS1 can inhibit the contraction and migration of collagen in fBMFs. The myofibroblast marker $\alpha$-SMA decreased in GAS5-AS1 overexpressed myofibroblasts, $\alpha$-SMA is positively correlated with the severity of OSF and the ability to wrinkle deformable substrates and enhance the shrinkage of collagen gels. Overall, those findings show that regulation of GAS5-AS1 expression reduces myofibroblast activation. This phenomenon may provide a great starting point for developing treatment methods to prevent OSF progression.

\section{Linc00084}

LINC00084 is an antisense transcript of the protein-coding gene nuclear enriched abundant transcript-1. LINC00084 is located on human chromosome 11q13.1. It is a nuclearretained lncRNA that uses the nuclear cytoplasmic RNA components of human fibroblasts and lymphoblasts. ${ }^{91}$ 
Usually, LINC00084 is found adjacent to the nucleus but, if the inflammasome is activated, it dissociates from the nucleus and moves to the cytoplasm. ${ }^{92}$ LINC00084 expression is increased substantially in oral precancerous lesions, and LINC00084 enhances the proliferation and invasion of oral cancer cells by regulating miR-365/ RGS20 signaling, so LINC00084 has been linked to the progression of oral cancer. ${ }^{93,94}$ Evidence also suggests that LINC00084 expression boosts the stress response and promotes OSF development. ${ }^{95}$ According to Lee and colleagues, LINC00084 is up-regulated in OSF tissues and myofibroblasts generated from OSF specimens, and is favorably linked with a number of fibrotic variables. ${ }^{34}$ Silencing LINC00084 expression has been shown to prevent arecoline-induced activities (eg, contraction and migration of collagen gel, and wound-healing capacities). LINC00084 interacts with miR-204, and prevents it from binding directly to ZEB1. The latter is an important transcription factor in EMT, and can upregulate $\alpha$-SMA expression and myofibroblast transdifferentiation from BMFs if it is induced by arecoline. ${ }^{96}$ Upregulation of LINC00084 expression stimulates ZEB1 expression, whereas ectopic expression of miR-204 suppresses it. Those findings suggest that inhibition of LINC00084 expression could help to reduce the fibrotic characteristics of fBMFs and slow the course of OSF.

Currently, a considerable number of IncRNAs have been discovered as miRNA sponges, and they play a key role in the onset and progression of various fibrosis. However, research into the role of lncRNA as a miRNA sponge in OSF is just being started. Only a few studies have been confirmed in vitro, and their influence on OSF has yet to be experimentally proven. New technologies, including as third-generation sequencing, can aid researchers in better understanding lncRNA and predicting its function, accelerating the field's progress. At the same time, it is necessary to learn from related research, such as the fibrosis mechanism of other organs.

\section{Regulatory Mechanisms of IncRNAs in OSF}

So far, lncRNAs are involved in various signaling pathways, such as TGF- $\beta$, PI3K/Akt/mTOR, MAPK/ERK, and $\mathrm{Wnt} / \beta$-catenin signaling pathways have been shown to regulate OSF. Studies have shown that targeting the $\mathrm{PI} 3 \mathrm{~K} / \mathrm{Akt} / \mathrm{mTOR}$ pathway can effectively treat the OSCC that occurs in the context of OSF. ${ }^{97}$ Activation of TGF- $\beta$ /
Smad signaling is considered to be one of the main reasons for inducing myofibroblast transdifferentiation in OSF. ${ }^{98}$ Those signaling pathways may also become critical therapeutic targets for OSF (Figure 2).

\section{TGF- $\beta /$ Smad Signaling Pathway}

The most common pro-fibrotic cytokine in OSF is TGF- $\beta$. It sends signals through Smad-dependent and non-Smad pathways, causing various biological effects in the process. ${ }^{99}$ Haque and colleagues showed TGF- $\beta$ expression to be upregulated in OSF tissue. ${ }^{100}$ The nuclear localization of p-SMAD2 in OSF tissue shows an activation effect. ${ }^{101,102}$ This activation of TGF- $\beta$ signal transduction in OSF tissue may be caused by upregulation of the ligand (TGF- $\beta 1$ ) and its two activating factors: $\alpha v \beta 6$ integrin and THBS- $1 .^{71}$ Expression of lncRNAs is dynamic, and several lncRNAs take part in the TGF- $\beta$ signaling pathway. This action leads to expression of the genes related to collagen accumulation and ECM protein-coding genes (eg, COL14A1, COL16A1, COL12A1, COL8A1) and myofibroblast differentiation. ${ }^{103}$ Recently, Lin et al ${ }^{33}$ studied the role and function of lncRNA GAS5 in OSF. They concluded that arecoline-induced upregulated expression of p-Smad2 is inhibited by GAS5-AS1 overexpression. Multiple RNA-Smad binding elements are found in GAS5 and compete with Smads to prevent them from binding to the promoter of the TGF- $\beta$ target gene. The TGF- $\beta /$ Smad signaling pathway is negatively regulated by it on the SBE. Fang et $\mathrm{al}^{54}$ found that LINC00974 may act as an upstream regulator of TGF- $\beta$ signaling after arecoline stimulation. Expression of several downstream targets of the TGF- $\beta$ pathway is increased in OSF tissues, and there is a positive correlation between LINC00974 expression and myofibroblast markers. In myofibroblasts inhibited by LINC00974, TGF- $\beta$ secretion and expression of phosphorylated smad 2 are inhibited. Yu et $\mathrm{al}^{31}$ demonstrated that lncRNA H19 is another downstream factor of TGF- $\beta 1$. TGF- $\beta$ expression is upregulated in arecolinestimulated BMFs, which induces upregulation of lncRNA H19 expression, and lncRNA H19 acts as a sponge of miR-29b and prevents its binding to COL1, thereby inhibiting the anti-fibrotic effect of miR-29b.

\section{PI3K/Akt Signaling Pathway}

EMT in OSCC and OSF is closely related to activation of the $\mathrm{PI} 3 \mathrm{~K} /$ Akt pathway. Inhibition of PI3K activation reduces ECM accumulation, whereas inhibition of Akt expression leads to a reduction of oral submucous fibroblast markers in 


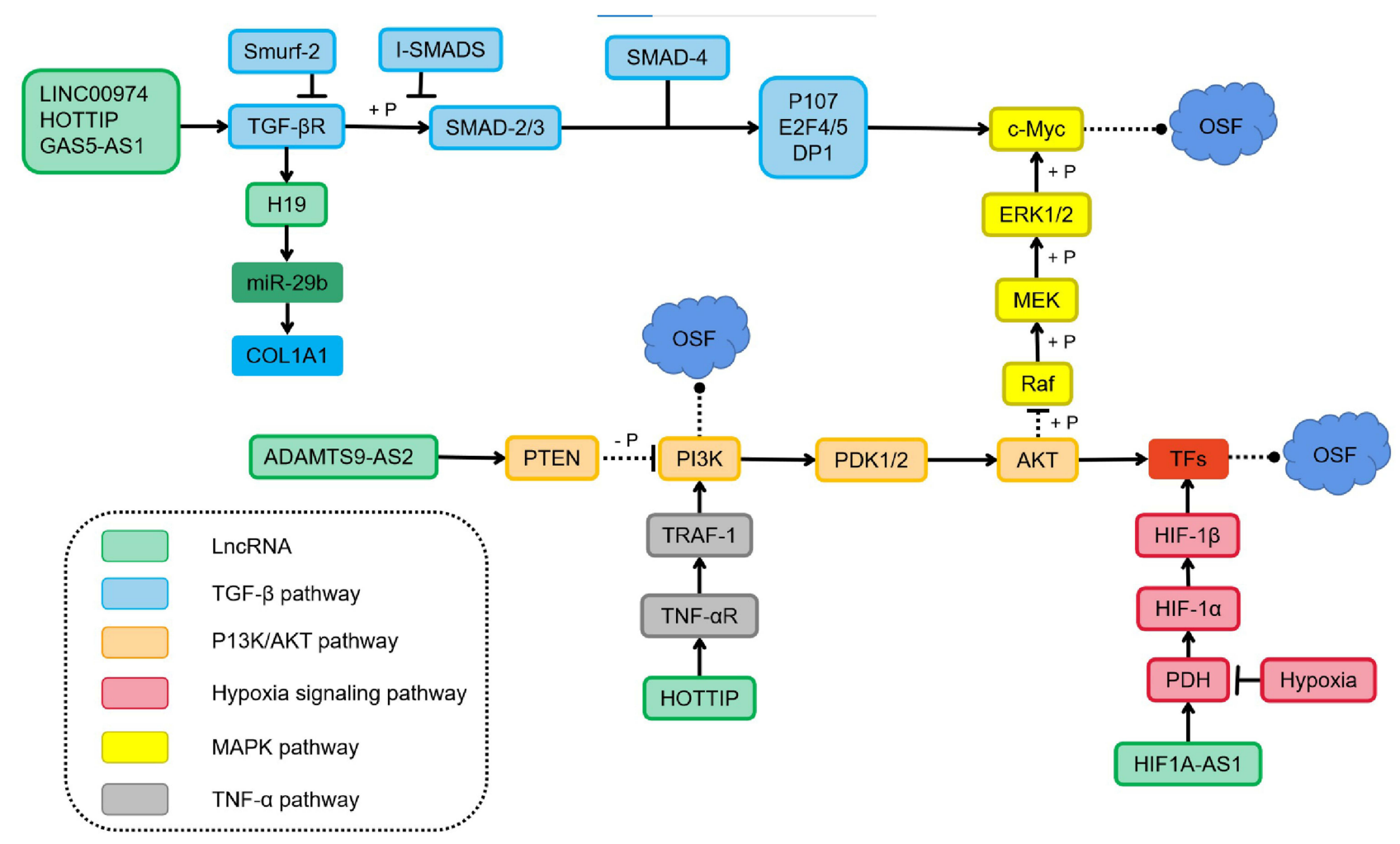

Figure 2 LncRNAs participate in the regulation of oral submucosal fibrosis through multiple signaling pathways. LINC00974 and GAS5-ASI activate the type I TGF- $\beta$ R and recruit the receptor-activated Smads, the R-Smads (Smad2/3), which are phosphorylated to form a complex with Smad4. The inhibitory Smads (I-Smads) negatively regulate the Smad activation by competing with Smad 2 and Smad3 for binding to the type I TGF- $\beta$ R. Feedback loops between transcription factors and HI 9 also regulate the TGF- $\beta$ induced EMT. Furthermore, Inhibition of ADAMTS9-AS2 and overexpression of HOTTIP involved in the PI3K/Akt signalling pathway could promote fBMFs activation and subsequently induce oral submucosal fibrosis.

OSF. $^{104}$ TGF- $\beta$ can activate PI3K/Akt and other Smadindependent signaling pathways to promote wound healing or fibrosis. ${ }^{105}$ TGF- $\beta$ activates PI3K through its receptor or transactivates it through epidermal growth factor and PDGF receptors. PI3K activation phosphorylates phosphatidylinositol 4,5-bisphosphate (PIP2) into phosphatidylinositol 3,4,5-triphosphate (PIP3), a phospholipid-membrane protein that binds to Akt. Upon binding, Akt is phosphorylated and activated by phosphoinositide-dependent kinase-1. Phosphatase and tensin homolog (PTEN) promote dephosphorylation of PIP3. ${ }^{106}$ PTEN is considered to be a negative regulator of myofibroblast differentiation in fibroproliferative diseases. The increase in TGF- $\beta$ expression in OSF may lead to a decrease in PTEN level and unrestricted Akt activity, thereby prolonging the survival time of fibroblasts and, ultimately, leading to fibrosis. ${ }^{107}$ In addition, the relationship between lncRNA and activation of the PI3K/Akt pathway has been studied recently. Through the analysis of miR target genes regulated by exosomal ADAMTS9-AS2, Zhou et al ${ }^{57}$ discovered several significantly enriched pathways: metabolic, PI3K-Akt signal transduction, and tumorigenesis. Exosomal
ADAMTS9-AS2 inhibited the malignant behavior of OSCC cells by modulating EMT and Akt signaling pathways.

\section{Hypoxia-Dependent Signaling Pathway}

Hypoxia-inducible factor (HIF) is the primary mediator of the well-known adaptive response to hypoxia in various pathophysiological processes. ${ }^{108,109}$ HIF is an essential helix-loop-helix transcription factor, consisting of a hypoxia-induced $\alpha$-subunit and a constitutively expressed nuclear $\beta$-subunit. If a sufficient level of oxygen is available, the conserved proline residues of HIF- $\alpha$ subunits are hydroxylated by HIF-prolyl hydroxylase domain protein $(\mathrm{PhD})$ and then serve as substrates for the ubiquitin ligase complex The von Hippel-Lindau protein that recognizes the component can identify hydroxylated HIF- $\alpha$, and degrade it rapidly by inducing E3 ubiquitination of $\alpha$ subunits. ${ }^{110}$ The enzyme activity of $\mathrm{PhD}$ is inhibited in hypoxic environments, so unmodified HIF- $\alpha$ escapes destruction and forms a functional complex with HIF- $\beta$ and its transcriptional co-activator $\mathrm{CBP} / \mathrm{p} 300 .^{110}$ This complex combines with the hypoxia response element 
(HRE) to regulate several HIF-regulated genes at the transcriptional level, thereby synergistically producing a series of compensatory responses to hypoxia at cellular and physiological levels. ${ }^{109,111}$ Hypoxia causes tissue fibrosis, leads to phenotypic changes, and promotes EMT. ${ }^{106}$ In a healthy person, HIF-1 $\alpha$ undergoes ubiquitination and subsequent proteasome degradation. ${ }^{106}$ Under hypoxic conditions, HIF- $1 \alpha$ is stable and interacts with coactivators such as p300/CBP to regulate its transcriptional activity. ${ }^{112}$ HIF- $1 \alpha$ can induce EMT by combining the promoter regions of $\mathrm{ZEB} 1^{113}$ and Snail1, ${ }^{114}$ thereby improving its trans activity and expression. HIF-1 $\alpha$ helps cells survive and proliferate in the early stage of cancerous transformation under hypoxic conditions..$^{75,115}$ Studies have shown that HIF1A-AS1 may be a new regulator of HIF- $1 \alpha$ and TGF- $\beta 3$ under oxidative stress because its expression is related directly to HIF- $1 \alpha$ expression. ${ }^{116}$ OSF pathophysiology is thought to be influenced by oxidative stress and TGF- $\beta$ signaling. ${ }^{117}$

Signal pathways such as TGF- $\beta$ and AKT appear to interact in the pathogenesis of OSF, according to a growing body of research. Although the cell biology of the TGF- $\beta$ and AKT pathways has been well documented in the pathophysiology of cell growth and many disorders, little is known about the mechanisms of these pro-fibrotic pathways in OSF. Simultaneously, the majority of research have focused on detecting pro-fibrotic cytokines and EMTrelated proteins (such as ZEB1). This suggests that lncRNAs are important in the development of OSF, although the exact regulation mechanism involving lncRNAs and these proteins is unknown. More research is needed to figure out the exact intricacies of how the lncRNA network influences OSF via signal transduction pathways like TGF- $\beta$.

\section{Future Expectations}

OSF is diagnosed primarily by a subjective clinical diagnosis, with histopathological analysis remaining the "gold standard" for the diagnosis. ${ }^{118}$ Tissue biopsy is an intrusive evaluation for which the test report can take a long time to be provided. ${ }^{9}$ If treated inappropriately, the suffering of OSF patients can be exacerbated. Some OSF patients refuse to have a biopsy, so a non-invasive, accurate detection tool to aid the clinical diagnosis is needed urgently.

With the emergence of "precision medicine" in fibrosis treatment, use of disease-specific biomarkers can help treatment adjustment for individuals or subgroups of patients. Compared with the fibrosis biomarkers used recently, increasing evidence suggests that dysregulated IncRNAs can cause (or be related to) the carcinogenesis of OSF. Therefore, IncRNAs may become promising biomarkers for OSF diagnosis. Through RNA sequencing of OSF patients, OSCC patients, and healthy controls, Zhou et $\mathrm{al}^{119}$ found 687 lncRNAs to show significantly different expression during OSF progression, of which 231 were upregulated and 456 were downregulated, Those data indicated that IncRNAs are involved in regulation of different stages of OSF development. Five newly discovered lncRNAs (HCG22, RP11-397A16.1, LINC00271, CTD3179P9.1, ZNF667-AS1) show different expression during OSF progression, which suggests the importance of these lncRNAs in the malignant development of OSF. However, clinical studies have involved only a small number of patients or healthy controls, so larger study cohorts and in vivo animal models are needed to determine the best new biomarkers.

Recently, development of biopsy of body fluids has shown less invasiveness, shorter waiting times for test reports, and greater patient acceptance. ${ }^{120}$ lncRNAs in biological fluids (eg, saliva, plasma) and exosomes are stable Hence, the precise detection of IncRNA profiles in biological fluids is attractive in clinical-translational research for biomarker development and diagnoses. ${ }^{121,122}$ Using real-time reverse transcription-quantitative polymerase chain reaction (RT-qPCR), expression of the IncRNA SAMMSON in the serum of OSCC patients and healthy controls was measured by Zheng and colleagues. ${ }^{123}$ They found that SAMMSON expression in the serum of OSCC patients was increased significantly compared with that of healthy controls, and that SAMMSON had high diagnostic sensitivity and specificity. Zhang et $\mathrm{al}^{124}$ discovered that expression of the IncRNA CASC15 in the plasma of OSCC patients was upregulated compared with that in patients with oral ulcers and in healthy controls, which suggested that CASC15 was a potential diagnostic biomarker of OSCC. In liquid biopsies, exosomes have abundant detectable targets, such as proteins, DNA, RNA, and lipids. ${ }^{125}$ Exosomes are key components of the oral microenvironment. They can promote or inhibit EMT, regulate the conversion of fibroblasts to myofibroblasts, help fibroblasts proliferate, and promote fibrosis in the process of immune regulation and mitochondrial damage. ${ }^{126}$ One can speculate that exosomes have unique advantages and potential in the screening and prognostic prediction of OSF. Therefore, quantities of lncRNAs can 


\section{IncRNA as the diagnostic marker}

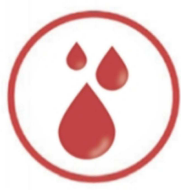

Blood

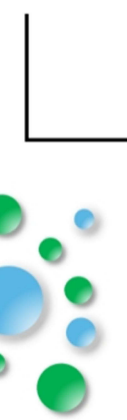

Exosome

Microvesicle

Apoptotic body

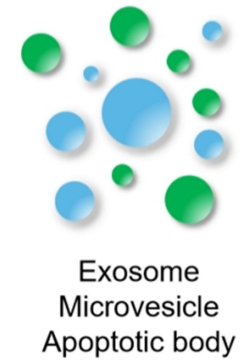

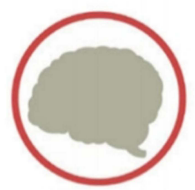

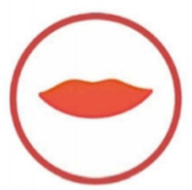

Cerebrospina fluid

\section{Saliva}

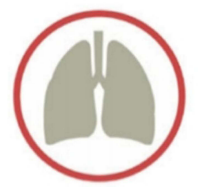

Alveolar lavage fluid

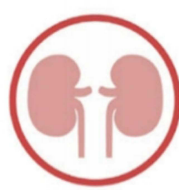

Urine

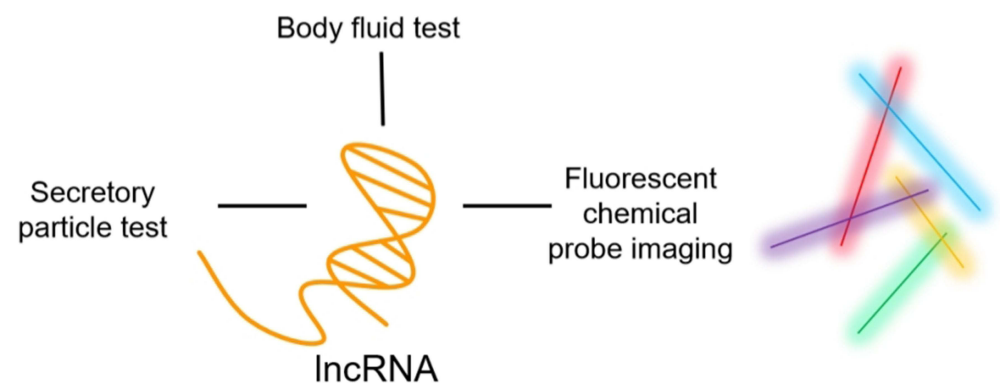

Figure 3 These images show various ways to use IncRNA as a diagnostic marker. Through minimally invasive sampling of cell-free fluids (blood, urine, saliva, cerebrospinal fluid, pleural effusion), quantitative detection of IncRNAs in exosomes, apoptotic bodies and extracellular vesicles. Fluorescent probe bioimaging technology can not only detect the abundance of clinically relevant biomarkers in OSF samples, but also detect their heterogeneity and spatial distribution.

be measured using RT-qPCR or high-throughput analysis if they are present in exosomes and extracellular vesicles.

Fluorescent probes have been used for non-invasive diagnoses in medical imaging. ${ }^{127}$ Compared with conventional protein probes, lncRNAs are the preferred potential targets because they are smaller molecules and are more diverse than proteins. ${ }^{128}$ Hence, the designed fluorescent probe can be synthesized readily, penetrate cells efficiently, and be used for in vivo imaging of OSF. Autofluorescence spectroscopy takes advantage of the fact that different diseased tissues have unique tissue morphologic characteristics. If tissue is excited to the appropriate wavelength, the internal fluorophores produce different fluorescence emission spectra. ${ }^{117}$ In recent years, scholars have developed a series of bright and stable fluorescent RNAs (referred to as "peppers"). These RNAs can be inserted into different non-coding and coding RNA sequences without affecting the transcription, localization, translation, or degradation of the target RNA and other vital functions, fluorescent labelling, and real-time imaging of various RNAs in living cells. ${ }^{129}$ These fluorescent RNAs can be used for real-time imaging in various situations, including OSF (Figure 3).

However, several unresolved problems persist. First, a specific disease may be related to multiple lncRNAs, and a given gene may be regulated by multiple lncRNAs.
Therefore, the interaction between IncRNAs may affect the protein expression of target genes and may complicate the potential role of lncRNAs as diagnostic markers of OSF. The specificity of established lncRNA targets should be verified before application. Second, lncRNAs, like other ncRNAs, are potential biomarkers. The design and identification methods in experiments are complicated, and these technologies must be standardized. In addition, lncRNAs lack clinical application, and current research conclusions are based on the results of only a small number of OSF patients. Often, there are large differences in results between different groups, and data reproducibility is lacking. Therefore, the accuracy and reproducibility of lncRNAs as biomarkers should be verified but, nevertheless, they are very attractive as simple and accurate biomarkers, especially for OSF.

\section{Conclusion}

Many new insights into OSF pathobiology have been gained as a result of intensive research of lncRNAs. Through the IncRNAs-miRs-mRNAs axis, IncRNAs can operate as miR sponges, and control expression of downstream pro-fibrotic molecules, which implies that lncRNAs are important regulators of OSF progression. IncRNAs from the blood samples or saliva samples of patients could be non-invasive clinical biomarkers (especially for 
early diagnosis) due to their exceptional stability as well as the simplicity and reproducibility of detection. However, research of IncRNAs in OSF is in its early stages, and much work must be done to fully comprehend the molecular mechanisms of lncRNAs and OSF. Our review covers a small portion of the lncRNAs involved in OSF development. More novel lncRNAs associated with OSF may be discovered soon thanks to new technologies such as high-throughput sequencing. Furthermore, due to the complexity of the regulatory network of lncRNAs, the underlying molecular mechanism of OSF is mostly unknown. As a result, additional in vitro and animalmodel investigations are required. If scholars can overcome some of the challenges associated with regulating these lncRNAs, patients with OSF may benefit greatly.

\section{Author Contributions}

All authors made a significant contribution to the work reported, whether that is in the conception, study design, execution, acquisition of data, analysis and interpretation, or in all these areas; took part in drafting, revising or critically reviewing the article; gave final approval of the version to be published; have agreed on the journal to which the article has been submitted; and agree to be accountable for all aspects of the work.

\section{Funding}

The National Natural Science Foundation of China [No. 31970677] -for the design of the study; Key Development and Research Projects in Anhui Province [201904a07020062] -for the collection and analysis of data.

\section{Disclosure}

The authors report no conflicts of interest for this work and have no affiliations with or involvement in any organization or entity with any financial interest or non-financial interest in the materials discussed in this paper.

\section{References}

1. Li J, Yao M, Zhu X, et al. YAP-Induced Endothelial-Mesenchymal transition in oral submucous fibrosis. J Dent Res. 2019;98(8):920-929. doi:10.1177/0022034519851804

2. Tom A, Baghirath V, Krishna B, et al. Ultrastructural changes of collagen in different histopathological grades of oral submucous fibrosis. J Pharm Bioallied Sci. 2019;11(Suppl 2):S309-S313. doi:10.4103/JPBS.JPBS_20_19

3. Wang YY, Tail YH, Wang WC, et al. Malignant transformation in 5071 southern Taiwanese patients with potentially malignant oral mucosal disorders. Bmc Oral Health. 2014;14:99. doi:10.1186/14726831-14-99
4. Ray JG, Chatterjee R, Chaudhuri K. Oral submucous fibrosis: a global challenge. Rising incidence, risk factors, management, and research priorities. Periodontol. 2019;80(1):200-212. doi:10.1111/prd.12277

5. Tilakaratne WM, Klinikowski MF, Saku T, Peters TJ, Warnakulasuriya S. Oral submucous fibrosis: review on aetiology and pathogenesis. Oral Oncol. 2006;42(6):561-568. doi:10.1016/ j.oraloncology.2005.08.005

6. Angadi PV, Rekha KP. Oral submucous fibrosis: a clinicopathologic review of 205 cases in Indians. Oral Maxillofac Surg. 2011;15 (1):15-19. doi:10.1007/s10006-010-0225-x

7. Jain A, Taneja S. Oral submucous fibrosis in pediatric patients: a systematic review and protocol for management. Int J Surg Oncol. 2019;2019:3497136.

8. Deshpande A, Kiran S, Dhillon S, Mallikarjuna R. Oral submucous fibrosis: a premalignant condition in a 14-year-old Indian girl. BMJ Case Rep. 2013;2013:2548.

9. Shen YW, Shih YH, Fuh LJ, Shieh TM. Oral submucous fibrosis: a review on biomarkers, pathogenic mechanisms, and treatments. Int J Mol Sci. 2020;21:19. doi:10.3390/ijms21197231

10. Arakeri G, Rai KK, Hunasgi S, et al. Oral submucous fibrosis: an update on current theories of pathogenesis. J Oral Pathol Med. 2017;46(6):406-412. doi:10.1111/jop.12581

11. Angadi PV, Rao SS. Areca nut in pathogenesis of oral submucous fibrosis: revisited. Oral Maxillofac Surg. 2011;15(1):1-9. doi:10.1007/s10006-010-0219-8

12. Arakeri G, Brennan PA. Oral submucous fibrosis: an overview of the aetiology, pathogenesis, classification, and principles of management. Br J Oral Maxillofac Surg. 2013;51(7):587-593. doi:10.1016/j.bjoms.2012.08.014

13. Bishen KA, Radhakrishnan R, Satyamoorthy K. The role of basic fibroblast growth factor in oral submucous fibrosis pathogenesis. J Oral Pathol Med. 2008;37(7):402-411. doi:10.1111/j.16000714.2008.00649.x

14. Haque MF, Harris M, Meghji S, Barrett AW. Immunolocalization of cytokines and growth factors in oral submucous fibrosis. Cytokine. 1998;10(9):713-719. doi:10.1006/cyto.1997.0342

15. Rajendran R, Rajeesh MP, Shaikh S, Shanthi MR. Expression of matrix metalloproteinases (MMP-1, MMP-2 and MMP-9) and their inhibitors (TIMP-1 and TIMP-2) in oral submucous fibrosis. Indian J Dent Res. 2006;17(4):161-166. doi:10.4103/ 0970-9290.29870

16. Shieh DH, Chiang LC, Shieh TY. Augmented mRNA expression of tissue inhibitor of metalloproteinase-1 in buccal mucosal fibroblasts by arecoline and safrole as a possible pathogenesis for oral submucous fibrosis. Oral Oncol. 2003;39(7):728-735. doi:10.1016/S1368-8375(03)00101-5

17. Jani YV, Chaudhary AR, Dudhia BB, et al. Evaluation of role of trace elements in oral submucous fibrosis patients: a study on Gujarati population. J Oral Maxillofac Pathol. 2017;21(3):455. doi:10.4103/jomfp.JOMFP_106_14

18. Alexander AJ, Ramani P, Sherlin HJ, Gheena S. Quantitative analysis of copper levels in areca nut plantation area - a role in increasing prevalence of oral submucous fibrosis: an in vitro study. Indian J Dent Res. 2019;30(2):261-266. doi:10.4103/ijdr. IJDR_431_17

19. Trivedy C, Meghji S, Warnakulasuriya KA, Johnson NW, Harris M. Copper stimulates human oral fibroblasts in vitro: a role in the pathogenesis of oral submucous fibrosis. J Oral Pathol Med. 2001;30 (8):465-470. doi:10.1034/j.1600-0714.2001.030008465.x

20. Rajendran R, Vijayakumar T, Vasudevan DM. An alternative pathogenetic pathway for oral submucous fibrosis (OSMF). Med Hypotheses. 1989;30(1):35-37. doi:10.1016/0306-9877(89)90122-9

21. Goel S, Ahmed J. A comparative study on efficacy of different treatment modalities of oral submucous fibrosis evaluated by clinical staging in population of Southern Rajasthan. $J$ Cancer Res Ther. 2015;11(1):113-118. doi:10.4103/0973-1482.139263 
22. Rajalalitha P, Vali S. Molecular pathogenesis of oral submucous fibrosis-a collagen metabolic disorder. J Oral Pathol Med. 2005;34(6):321-328. doi:10.1111/j.1600-0714.2005.00325.x

23. Cech TR, Steitz JA. The noncoding RNA revolution-trashing old rules to forge new ones. Cell. 2014;157(1):77-94.

24. Heo MJ, Yun J, Kim SG. Role of non-coding RNAs in liver disease progression to hepatocellular carcinoma. Arch Pharm Res. 2019;42(1):48-62. doi:10.1007/s12272-018-01104-x

25. Van der Hauwaert C, Glowacki F, Pottier N, Cauffiez C. NonCoding RNAs as new therapeutic targets in the context of renal fibrosis. Int J Mol Sci. 2019;20:8. doi:10.3390/ijms20081977

26. Zheng L, Jian X, Guo F, et al. MiR-203 inhibits arecoline-induced epithelial-mesenchymal transition by regulating secreted frizzled-related protein 4 and transmembrane-4 L six family member 1 in oral submucous fibrosis. Oncol Rep. 2015;33 (6):2753-2760. doi:10.3892/or.2015.3909

27. Lu MY, Yu CC, Chen PY, et al. MiR-200c inhibits the arecoline-associated myofibroblastic transdifferentiation in buccal mucosal fibroblasts. J Formos Med Assoc. 2018;117(9):791-797. doi:10.1016/j.jfma.2018.05.016

28. Liao YW, Yu CC, Hsieh PL, Chang YC. MiR-200b ameliorates myofibroblast transdifferentiation in precancerous oral submucous fibrosis through targeting ZEB2. J Cell Mol Med. 2018;22 (9):4130-4138. doi:10.1111/jcmm. 13690

29. Kazimierczyk M, Wrzesinski J. Long Non-Coding RNA epigenetics. Int J Mol Sci. 2021;22(11):6166. doi:10.3390/ ijms22116166

30. Wang W, Min L, Qiu X, et al. Biological function of long non-coding RNA (LncRNA) xist. Front Cell Dev Biol. 2021;9:645647.

31. Yu CC, Liao YW, Hsieh PL, Chang YC. Targeting lncRNA H19/ miR-29b/COL1A1 axis impedes myofibroblast activities of precancerous oral submucous fibrosis. Int J Mol Sci. 2021;22(4):124

32. Lee YH, Yu CC, Hsieh PL, et al. Inhibition of lncRNA HOTTIP ameliorated myofibroblast activities and inflammatory cytokines in oral submucous fibrosis. J Formos Med Assoc. 2021;120 (5):1188-1193. doi:10.1016/j.jfma.2020.11.013

33. Lin CY, Liao YW, Hsieh PL, et al. LncRNA GAS5-AS1 inhibits myofibroblasts activities in oral submucous fibrosis. J Formos Med Assoc. 2018;117(8):727-733. doi:10.1016/j.jfma.2017.09.012

34. Lee YH, Liao YW, Lu MY, Hsieh PL, Yu CC. LINC00084/miR204/ZEB1 axis mediates myofibroblastic differentiation activity in fibrotic buccal mucosa fibroblasts: therapeutic target for oral submucous fibrosis. J Pers Med. 2021;11(8):707. doi:10.3390/ jpm11080707

35. Miao H, Wu XQ, Zhang DD, et al. Deciphering the cellular mechanisms underlying fibrosis-associated diseases and therapeutic avenues. Pharmacol Res. 2021;163:105316. doi:10.1016/j. phrs.2020.105316

36. Lei CS, Kung HJ, Shih JW. Long Non-Coding RNAs as functional codes for oral cancer: translational potential, progress and promises. Int $J$ Mol Sci. 2021;22(9):4903. doi:10.3390/ ijms22094903

37. Kopp F, Mendell JT. Functional classification and experimental dissection of long noncoding RNAs. Cell. 2018;172(3):393-407. doi:10.1016/j.cell.2018.01.011

38. He W, Zhong G, Jiang N, et al. Long noncoding RNA BLACAT2 promotes bladder cancer-associated lymphangiogenesis and lymphatic metastasis. J Clin Invest. 2018;128(2):861-875. doi:10.1172/JCI96218

39. de Klerk E, Hp T. Alternative mRNA transcription, processing, and translation: insights from RNA sequencing. Trends Genet. 2015;31(3):128-139. doi:10.1016/j.tig.2015.01.001

40. Yang Y, Wen L, Zhu H. Unveiling the hidden function of long non-coding RNA by identifying its major partner-protein. Cell Biosci. 2015;5:59. doi:10.1186/s13578-015-0050-х
41. Rinn JL, Chang HY. Genome regulation by long noncoding RNAs. Annu Rev Biochem. 2012;81:145-166. doi:10.1146/ annurev-biochem-051410-092902

42. Balas MM, Johnson AM. Exploring the mechanisms behind long noncoding RNAs and cancer. Noncoding RNA Res. 2018;3 (3):108-117. doi:10.1016/j.ncrna.2018.03.001

43. Rosa S, Duncan S, Dean C. Mutually exclusive sense-antisense transcription at FLC facilitates environmentally induced gene repression. Nat Commun. 2016;7:13031. doi:10.1038/ncomms13031

44. Csorba T, Questa JI, Sun Q, Dean C. Antisense COOLAIR mediates the coordinated switching of chromatin states at FLC during vernalization. Proc Natl Acad Sci US A. 2014;111 (45):16160-16165. doi:10.1073/pnas.1419030111

45. Gao N, Li Y, Li J, et al. Long Non-Coding RNAs: the regulatory mechanisms, research strategies, and future directions in cancers. Front Oncol. 2020;10:598817. doi:10.3389/fonc.2020.598817

46. Cheng S, Xia B, Li H, et al. Long non-coding RNA SATB2-AS1 inhibits microRNA-155-3p to suppress breast cancer cell growth by promoting breast cancer metastasis suppressor 1-like. Cancer Cell Int. 2020;20(1):321. doi:10.1186/s12935-020-01411-8

47. $\mathrm{Wu} \mathrm{R}, \mathrm{Su} \mathrm{Y}, \mathrm{Wu} \mathrm{H}$, et al. Characters, functions and clinical perspectives of long non-coding RNAs. Mol Genet Genomics. 2016;291(3):1013-1033. doi:10.1007/s00438-016-1179-y

48. Puvvula PK, Desetty RD, Pineau $\mathrm{P}$, et al. Long noncoding RNA PANDA and scaffold-attachment-factor SAFA control senescence entry and exit. Nat Commun. 2014;5:5323. doi:10.1038/ncomms6323

49. Gil N, Ulitsky I. Production of spliced long noncoding RNAs specifies regions with increased enhancer activity. Cell Syst. 2018;7(5):537-547.

50. Tan JY, Biasini A, Young RS, Marques AC. Splicing of enhancer-associated lincRNAs contributes to enhancer activity. Life Sci Alliance. 2020;3(4):1-8.

51. Neppl RL, Wu CL, Walsh K. LncRNA Chronos is an aging-induced inhibitor of muscle hypertrophy. $J$ Cell Biol. 2017;216(11):3497-3507. doi:10.1083/jcb.201612100

52. Wang Z, Yang B, Zhang M, et al. LncRNA epigenetic landscape analysis identifies EPIC1 as an oncogenic lncRNA that interacts with MYC and promotes Cell-Cycle progression in cancer. Cancer Cell. 2018;33(4):706-720.

53. Briggs JA, Wolvetang EJ, Mattick JS, Rinn JL, Barry G. Mechanisms of long non-coding RNAs in mammalian nervous system development, plasticity, disease, and evolution. Neuron. 2015;88(5):861-877. doi:10.1016/j.neuron.2015.09.045

54. Fang CY, Yu CC, Liao YW, et al. LncRNA LINC00974 activates TGF-beta/Smad signaling to promote oral fibrogenesis. J Oral Pathol Med. 2019;48(2):151-158.

55. Wang YK, Liu CM, Lin T, et al. Inhibition of HIF1A-AS1 impedes the arecoline-induced migration activity of human oral mucosal fibroblasts. J Formos Med Assoc. 2020;119(4):879-883. doi:10.1016/j.jfma.2019.12.014

56. Yu CH, Fang CY, Yu CC, et al. LINC00312/YBX1 axis regulates myofibroblast activities in oral submucous fibrosis. Int J Mol Sci. 2020;21(8):2979.

57. Zhou S, Zhu Y, Li Z, et al. Exosome-derived long non-coding RNA ADAMTS9-AS2 suppresses progression of oral submucous fibrosis via AKT signalling pathway. J Cell Mol Med. 2021;25 (4):2262-2273. doi:10.1111/jcmm.16219

58. Leibovitch MP, Nguyen VC, Gross MS, et al. The human ASM (adult skeletal muscle) gene: expression and chromosomal assignment to 11p15. Biochem Biophys Res Commun. 1991;180 (3):1241-1250. doi:10.1016/S0006-291X(05)81329-4

59. Poirier F, Chan CT, Timmons PM, et al. The murine H19 gene is activated during embryonic stem cell differentiation in vitro and at the time of implantation in the developing embryo. Development. 1991;113(4):1105-1114. doi:10.1242/dev.113.4.1 105 
60. Tabano S, Colapietro P, Cetin I, et al. Epigenetic modulation of the IGF2/H19 imprinted domain in human embryonic and extra-embryonic compartments and its possible role in fetal growth restriction. Epigenetics-Us. 2010;5(4):313-324. doi:10.4161/epi.5.4.11637

61. Hao Y, Crenshaw T, Moulton T, Newcomb E, Tycko B. Tumoursuppressor activity of H19 RNA. Nature. 1993;365 (6448):764-767. doi:10.1038/365764a0

62. Zhang DM, Lin ZY, Yang ZH, et al. IncRNA H19 promotes tongue squamous cell carcinoma progression through beta-catenin/GSK3beta/EMT signaling via association with EZH2. Am J Transl Res. 2017;9(7):3474-3486.

63. Wu T, Qu L, He G, et al. Regulation of laryngeal squamous cell cancer progression by the IncRNA H19/miR-148a-3p/DNMT1 axis. Oncotarget. 2016;7(10):11553-11566. doi:10.18632/oncotarget.7270

64. Lu Q, Guo Z, Xie W, et al. The lncRNA h19 mediates pulmonary fibrosis by regulating the miR-196a/COL1A1 axis. Inflammation. 2018;41(3):896-903. doi:10.1007/s10753-018-0744-4

65. Choong OK, Chen CY, Zhang J, et al. Hypoxia-induced H19/ YB-1 cascade modulates cardiac remodeling after infarction. Theranostics. 2019;9(22):6550-6567. doi:10.7150/thno.35218

66. Kuo MY, Chen HM, Hahn LJ, Hsieh CC, Chiang CP. Collagen biosynthesis in human oral submucous fibrosis fibroblast cultures. $J$ Dent Res. 1995;74(11):1783-1788. doi:10.1177/002203459 50740111101

67. Wang KC, Yang YW, Liu B, et al. A long noncoding RNA maintains active chromatin to coordinate homeotic gene expression. Nature. 2011;472(7341):120-124. doi:10.1038/nature09819

68. Ghafouri-Fard S, Dashti S, Taheri M. The HOTTIP (HOXA transcript at the distal tip) lncRNA: review of oncogenic roles in human. Biomed Pharmacother. 2020;127:110158. doi:10.1016/ j.biopha.2020.110158

69. Wang KC, Yang YW, Liu B, et al. A long noncoding RNA maintains active chromatin to coordinate homeotic gene expression. Nature. 2011;472(7341):120-124.

70. Huang GZ, Wu QQ, Zheng ZN, Shao TR, Lv XZ. Identification of candidate biomarkers and analysis of prognostic values in oral squamous cell carcinoma. Front Oncol. 2019;9:1054. doi:10.3389/fonc.2019.01054

71. Khan I, Kumar N, Pant I, Narra S, Kondaiah P. Activation of TGF-beta pathway by areca nut constituents: a possible cause of oral submucous fibrosis. PLoS One. 2012;7(12):e51806. doi:10.1371/journal.pone.0051806

72. Bertozzi D, Iurlaro R, Sordet O, et al. Characterization of novel antisense HIF-1alpha transcripts in human cancers. Cell Cycle. 2011;10(18):3189-3197. doi:10.4161/cc.10.18.17183

73. Lee SS, Tsai CH, Yang SF, Ho YC, Chang YC. Hypoxia inducible factor-1alpha expression in areca quid chewing-associated oral squamous cell carcinomas. Oral Dis. 2010;16(7):696-701. doi:10.1111/j.1601-0825.2010.01680.x

74. Uehara M, Sano K, Ikeda H, Nonaka M, Asahina I. Hypoxiainducible factor 1 alpha in oral squamous cell carcinoma and its relation to prognosis. Oral Oncol. 2009;45(3):241-246. doi:10.1016/j.oraloncology.2008.05.007

75. Tilakaratne WM, Iqbal Z, Teh MT, et al. Upregulation of HIF-1alpha in malignant transformation of oral submucous fibrosis. J Oral Pathol Med. 2008;37(6):372-377. doi:10.1111/ j.1600-0714.2007.00625.x

76. Deng L, Jing N, Tan G, et al. A common region of allelic loss on chromosome region 3p25.3-26.3 in nasopharyngeal carcinoma. Genes Chromosomes Cancer. 1998;23(1):21-25. doi:10.1002/ (SICI)1098-2264(199809)23:1<21::AID-GCC4>3.0.CO;2-8

77. $\mathrm{Yu} \mathrm{H}, \mathrm{Xu} \mathrm{Q}$, Liu $\mathrm{F}$, et al. Identification and validation of long noncoding RNA biomarkers in human non-small-cell lung carcinomas. J Thorac Oncol. 2015;10(4):645-654. doi:10.1097/ JTO.0000000000000470
78. Xie Y, Bin L, Yang J, et al. Molecular cloning and characterization of NAG-7: a novel gene downregulated in human nasopharyngeal carcinoma. Chin Med J. 2001;114(5):530-534.

79. Min X, Liu K, Zhu H, Zhang J. Long noncoding RNA LINC003121 inhibits proliferation and invasion of thyroid cancer cells by suppression of the Phosphatidylinositol-3-Kinase (PI3K)/ Akt signaling pathway. Med Sci Monit. 2018;24:4592-4601. doi:10.12659/MSM.908652

80. Li G, Wang C, Wang Y, Xu B, Zhang W. LINC00312 represses proliferation and metastasis of colorectal cancer cells by regulation of miR-21. J Cell Mol Med. 2018;22(11):5565-5572. doi:10.1111/jcmm.13830

81. Wu J, Zhou X, Fan Y, et al. Long non-coding RNA 00312 downregulates cyclin B1 and inhibits hepatocellular carcinoma cell proliferation in vitro and in vivo. Biochem Biophys Res Commun. 2018;497(1):173-180. doi:10.1016/j.bbrc.2018.02.049

82. Hinz B, Celetta G, Tomasek JJ, Gabbiani G, Chaponnier C. Alpha-smooth muscle actin expression upregulates fibroblast contractile activity. Mol Biol Cell. 2001;12(9):2730-2741. doi:10.1091/mbc.12.9.2730

83. Tsai CC, Ma RH, Shieh TY. Deficiency in collagen and fibronectin phagocytosis by human buccal mucosa fibroblasts in vitro as a possible mechanism for oral submucous fibrosis. J Oral Pathol Med. 1999;28(2):59-63. doi:10.1111/j.1600-0714.1999.tb01997.x

84. Nam RK, Zhang WW, Loblaw DA, et al. A genome-wide association screen identifies regions on chromosomes $1 \mathrm{q} 25$ and $7 \mathrm{p} 21$ as risk loci for sporadic prostate cancer. Prostate Cancer Prostatic Dis. 2008;11(3):241-246. doi:10.1038/sj.pcan.4501010

85. Smith CM, Steitz JA. Classification of gas5 as a multi-smallnucleolar-RNA (snoRNA) host gene and a member of the 5'terminal oligopyrimidine gene family reveals common features of snoRNA host genes. Mol Cell Biol. 1998;18(12):6897-6909. doi:10.1128/MCB.18.12.6897

86. Raho G, Barone V, Rossi D, Philipson L, Sorrentino V. The gas 5 gene shows four alternative splicing patterns without coding for a protein. Gene. 2000;256(1-2):13-17. doi:10.1016/S03781119(00)00363-2

87. Kino T, Hurt DE, Ichijo T, Nader N, Chrousos GP. Noncoding RNA gas5 is a growth arrest- and starvation-associated repressor of the glucocorticoid receptor. Sci Signal. 2010;3(107):a8. doi:10.1126/scisignal.2000568

88. Mourtada-Maarabouni M, Hedge VL, Kirkham L, Farzaneh F, Williams GT. Growth arrest in human T-cells is controlled by the non-coding RNA growth-arrest-specific transcript 5 (GAS5). $J$ Cell Sci. 2008;121(Pt 7):939-946. doi:10.1242/jcs.024646

89. Bian EB, Xiong ZG, Li J. New advances of lncRNAs in liver fibrosis, with specific focus on IncRNA-miRNA interactions. J Cell Physiol. 2019;234(3):2194-2203. doi:10.1002/jcp.27069

90. Wu Y, Lyu H, Liu H, et al. Downregulation of the long noncoding RNA GAS5-AS1 contributes to tumor metastasis in non-small cell lung cancer. Sci Rep. 2016;6:31093. doi:10.1038/srep31093

91. Hutchinson JN, Ensminger AW, Clemson CM, et al. A screen for nuclear transcripts identifies two linked noncoding RNAs associated with SC35 splicing domains. Bmc Genomics. 2007;8:39. doi:10.1186/1471-2164-8-39

92. Zhang P, Cao L, Zhou R, Yang X, Wu M. The lncRNA Neat1 promotes activation of inflammasomes in macrophages. Nat Commun. 2019;10(1):1495. doi:10.1038/s41467-019-09482-6

93. Jia H, Wang X, Sun Z. Exploring the molecular pathogenesis and biomarkers of high risk oral premalignant lesions on the basis of long noncoding RNA expression profiling by serial analysis of gene expression. Eur J Cancer Prev. 2018;27(4):370-378. doi:10.1097/CEJ.0000000000000346

94. Huang G, He X, Wei XL. LncRNA NEAT1 promotes cell proliferation and invasion by regulating miR365/RGS20 in oral squamous cell carcinoma. Oncol Rep. 2018;39(4):1948-1956. 
95. An H, Tan JT, Shelkovnikova TA. Stress granules regulate stress-induced paraspeckle assembly. J Cell Biol. 2019;218 (12):4127-4140. doi:10.1083/jcb.201904098

96. Chang YC, Tsai CH, Lai YL, et al. Arecoline-induced myofibroblast transdifferentiation from human buccal mucosal fibroblasts is mediated by ZEB1. J Cell Mol Med. 2014;18(4):698-708. doi:10.1111/jcmm.12219

97. Wang J, Jiang C, Li N, et al. The circEPSTI1/mir-942-5p/LTBP2 axis regulates the progression of OSCC in the background of OSF via EMT and the PI3K/Akt/mTOR pathway. Cell Death Dis. 2020;11(8):682. doi:10.1038/s41419-020-02851-w

98. Khan I, Kumar N, Pant I, Narra S, Kondaiah P. Activation of TGF-beta pathway by areca nut constituents: a possible cause of oral submucous fibrosis. PLoS One. 2012;7(12):e51806.

99. Shetty SS, Sharma M, Fonseca FP, et al. Signaling pathways promoting epithelial mesenchymal transition in oral submucous fibrosis and oral squamous cell carcinoma. Jpn Dent Sci Rev. 2020;56(1):97-108. doi:10.1016/j.jdsr.2020.07.002

100. Haque MF, Meghji S, Khitab U, Harris M. Oral submucous fibrosis patients have altered levels of cytokine production. J Oral Pathol Med. 2000;29(3):123-128. doi:10.1034/j.16000714.2000.290304.x

101. Moutasim KA, Jenei V, Sapienza K, et al. Betel-derived alkaloid up-regulates keratinocyte alphavbeta6 integrin expression and promotes oral submucous fibrosis. $J$ Pathol. 2011;223 (3):366-377. doi:10.1002/path.2786

102. Khan I, Agarwal P, Thangjam GS, et al. Role of TGF-beta and BMP7 in the pathogenesis of oral submucous fibrosis. Growth Factors. 2011;29(4):119-127. doi:10.3109/08977194.2011.582839

103. Huang ZP, Ding Y, Chen J, et al. Long non-coding RNAs link extracellular matrix gene expression to ischemic cardiomyopathy. Cardiovasc Res. 2016;112(2):543-554. doi:10.1093/cvr/cvw201

104. Monteiro R, Hallikeri K, Sudhakaran A. PTEN and alpha-SMA expression and diagnostic role in oral submucous fibrosis and oral squamous cell carcinoma with concomitant oral submucous fibrosis. J Oral Maxillofac Res. 2021;12(1):e3. doi:10.5037/jomr.2021.12103

105. Suwanabol PA, Seedial SM, Zhang F, et al. TGF-beta and Smad3 modulate $\mathrm{PI} 3 \mathrm{~K} /$ Akt signaling pathway in vascular smooth muscle cells. Am J Physiol Heart Circ Physiol. 2012;302(11):H2211H2219. doi:10.1152/ajpheart.00966.2011

106. Gonzalez DM, Medici D. Signaling mechanisms of the epithelial-mesenchymal transition. Sci Signal. 2014;7(344):e8. doi:10.1126/scisignal.2005189

107. Angadi PV, Krishnapillai R. Evaluation of PTEN immunoexpression in oral submucous fibrosis: role in pathogenesis and malignant transformation. Head Neck Pathol. 2012;6(3):314-321. doi:10.1007/s12105-012-0341-z

108. Nangaku M, Inagi R, Miyata T, Fujita T. Hypoxia and hypoxia-inducible factor in renal disease. Nephron Exp Nephrol. 2008;110(1):e1-e7. doi:10.1159/000148256

109. Nangaku M, Eckardt KU. Hypoxia and the HIF system in kidney disease. J Mol Med (Berl). 2007;85(12):1325-1330. doi:10.1007/ s00109-007-0278-y

110. Liu M, Ning X, Li R, et al. Signalling pathways involved in hypoxia-induced renal fibrosis. J Cell Mol Med. 2017;21 (7):1248-1259. doi:10.1111/jcmm. 13060

111. Eckardt KU, Bernhardt W, Willam C, Wiesener M. Hypoxia-inducible transcription factors and their role in renal disease. Semin Nephrol. 2007;27(3):363-372. doi:10.1016/j.semnephrol.2007.02.007
112. Masoud GN, Li W. HIF-1alpha pathway: role, regulation and intervention for cancer therapy. Acta Pharm Sin B. 2015;5 (5):378-389. doi:10.1016/j.apsb.2015.05.007

113. Zhang W, Shi X, Peng Y, et al. HIF-1alpha promotes Epithelial-Mesenchymal transition and metastasis through direct regulation of ZEB1 in colorectal cancer. PLoS One. 2015;10(6):e129603.

114. Zhu Y, Tan J, Xie H, et al. HIF-1alpha regulates EMT via the Snail and beta-catenin pathways in paraquat poisoning-induced early pulmonary fibrosis. J Cell Mol Med. 2016;20(4):688-697. doi:10.1111/jcmm.12769

115. Chaudhary M, Bajaj S, Bohra S, Swastika N, Hande A. The domino effect: role of hypoxia in malignant transformation of oral submucous fibrosis. J Oral Maxillofac Pathol. 2015;19 (2):122-127. doi:10.4103/0973-029X.164519

116. Acun A, Zorlutuna P. Engineered myocardium model to study the roles of HIF-1alpha and HIF1A-AS1 in paracrine-only signaling under pathological level oxidative stress. Acta Biomater. 2017;58:323-336. doi:10.1016/j.actbio.2017.06.023

117. Shih YH, Wang TH, Shieh TM, Tseng YH. Oral Submucous Fibrosis: a Review on Etiopathogenesis, Diagnosis, and Therapy. Int J Mol Sci. 2019;20:12. doi:10.3390/ijms20122940

118. More CB, Rao NR. Proposed clinical definition for oral submucous fibrosis. J Oral Biol Craniofac Res. 2019;9(4):311-314. doi:10.1016/j.jobcr.2019.06.016

119. Zhou S, Zhu Y, He Z, et al. Long Non-Coding RNA expression profile associated with malignant progression of oral submucous fibrosis. J Oncol. 2019;2019:6835176. doi:10.1155/2019/6835176

120. De Rubis G, Rajeev KS, Bebawy M. Liquid biopsies in cancer diagnosis, monitoring, and prognosis. Trends Pharmacol Sci. 2019;40(3):172-186. doi:10.1016/j.tips.2019.01.006

121. Arantes L, De Carvalho AC, Melendez ME, Lopes CA. Serum, plasma and saliva biomarkers for head and neck cancer. Expert Rev Mol Diagn. 2018;18(1):85-112. doi:10.1080/14737159.2017.14 04906

122. Lousada-Fernandez F, Rapado-Gonzalez O, Lopez-Cedrun JL, et al. Liquid biopsy in oral cancer. Int J Mol Sci. 2018;19 (6):1704. doi:10.3390/ijms19061704

123. Zheng X, Tian X, Zhang Q, Shi P, Li S. Long non-coding RNA SAMMSON as a novel potential diagnostic and prognostic biomarker for oral squamous cell carcinoma. J Dent Sci. 2020;15 (3):329-335. doi:10.1016/j.jds.2019.11.008

124. Zhang X, Guo B, Zhu Y, et al. Up-regulation of plasma lncRNA CACS15 distinguished early-stage oral squamous cell carcinoma patient. Oral Dis. 2020;26(8):1619-1624. doi:10.1111/odi.13245

125. Languino LR, Singh A, Prisco M, et al. Exosome-mediated transfer from the tumor microenvironment increases TGFbeta signaling in squamous cell carcinoma. Am J Transl Res. 2016;8(5):2432-2437.

126. Xie L, Zeng Y. Therapeutic potential of exosomes in pulmonary fibrosis. Front Pharmacol. 2020;11:590972. doi:10.3389/ fphar.2020.590972

127. Gao M, Yu F, Lv C, Choo J, Chen L. Fluorescent chemical probes for accurate tumor diagnosis and targeting therapy. Chem Soc Rev. 2017;46(8):2237-2271.

128. Zhang S, Chen H, Yue D, et al. Long non-coding RNAs: promising new targets in pulmonary fibrosis. J Gene Med. 2021;23(3): e3318. doi:10.1002/jgm.3318

129. Chen X, Zhang D, Su N, et al. Visualizing RNA dynamics in live cells with bright and stable fluorescent RNAs. Nat Biotechnol. 2019;37(11):1287-1293. doi:10.1038/s41587-019-0249-1 


\section{Publish your work in this journal}

The Journal of Inflammation Research is an international, peerreviewed open-access journal that welcomes laboratory and clinical findings on the molecular basis, cell biology and pharmacology of inflammation including original research, reviews, symposium reports, hypothesis formation and commentaries on: acute/chronic inflammation; mediators of inflammation; cellular processes; molecular mechanisms; pharmacology and novel anti-inflammatory drugs; clinical conditions involving inflammation. The manuscript management system is completely online and includes a very quick and fair peerreview system. Visit http://www.dovepress.com/testimonials.php to read real quotes from published authors. 